\title{
УДК 332.234.4:631.1:528.8:55:002.6
}

\section{МОНИТОРИНГ СОСТОЯНИЯ РАСТИТЕЛЬНОГО ПОКРОВА ТЕРРИТОРИИ ЦЕНТРАЛЬНОГО ИРАКА С ИСПОЛЬЗОВАНИЕМ СПУТНИКОВЫХ ДАННЫХ LANDSAT-8}

\author{
Токарева Ольга Сергеевна'1, \\ ost@tpu.ru
}

\author{
Пасько Ольга Анатольевна ${ }^{1}$, \\ oap@tpu.ru
}

Маджид Саиф Моханад',
ostokareva@gmail.com

\author{
Кабраль Педро², \\ pcabral@novaims.unl.pt \\ 1 Национальный исследовательский Томский политехнический университет, \\ Россия, 634050, г. Томск, пр. Ленина, 30. \\ 2 Лиссабонский университет, \\ Португалия, г. Лиссабон, 1070-312.
}

\begin{abstract}
Актуальность исследования обусловлена необходимостью получения объективной инфрормации о закономерностях территориально-временной изменчивости состояния растительности в республике Ирак и о факторах, ее определяющих, для максимально эффективного использования земель в экстремальных природных и социально-экономических условиях хозяйствования.

Цель: анализ динамики состояния растительного покрова территорий четырех провинций Центрального Ирака с использованием нормализованного разностного вегетационного индекса NDVI в период с 2014 по 2017 г2.

Объектом исследования являются территории четырех провинций Центрального Ирака: Бабиля, Багдада, Васита и Диялы. Предмет исследования - временно-территориальная изменчивость состояния растительности.

Методы: дистанционного зондирования Земли, тематического картирования, обработки изображений, пространственного анализа данных, статистического анализа.

Результаты. С использованием вегетационного индекса, рассчитанного по данным дистанционного зондирования Земли, полученным co сnутника Landsat-8, выявлены закономерности временно-территориальной динамики состояния растительности территории Центрального Ирака. Установлены региональные особенности, проявившиеся в структуре растительности и скорости ее изменения. Максимальные площади земель, не покрытых растительностью, выявлены в провинциях Багдад и Васит; покрытых растительностью большинства классов - также в Васите; покрытых плотной растительностью - в Дияле, отмеченной также минимумом бесплодных территорий. Бабиль характеризуется минимальной площадью, покрытой растительностью. Багдад по изученным показателям занимает промежуточное положение. Данные закономерности слабо согласуются с абсолютными значениями площадей провинций. Они вызваны сложившимися условиями хозяйствования и проявляются в качественной и количественной неоднородности распределения растительности по провинциям. Во время активной стадии вегетации, при переходе от февраля к марту, вариации площадей, не занятых растительностью, занятых умеренной и плотной растительностью, стабильны; в то же время происходит рост вариации площадей с очень плотной и падение площадей со слабой растительностью и растительностью максимальной плотности. Корреляционньй анализ между показателями NDVI и погодными условиями достоверных связей не выявил.
\end{abstract}

\section{Ключевые слова:}

Вегетационный индекс, геоинформационная система, данные дистанционного зондирования, классы растительности, сельское хозяйство, Центральный Ирак.

\section{Введение}

В процессе изменения климата и деятельности человека в мире происходит прогрессирующая деградация земель [1], которая ведет к снижению плодородия почвы, сокращению площади пашни и ухудшению качества жизни населения [2]. В засушливых, полузасушливых и сухих субгумидных районах культурные растения возделывают вблизи границ их экологической толерантности, поэтому они особенно чувствительны к изменениям внешней среды, и сельскохозяйственное производство связано с высокими рисками. С другой стороны, игнорирование биологических особенностей почв ведет к деградации сельскохозяй- ственных (с.-х.) земель [3-5] и проявляется в форме засоления, опустынивания почв, снижения биологической продуктивности экосистем и др. [6, 7]. Для предотвращения деградации требуется комплекс организационно-хозяйственных и технических мероприятий, таких как искусственное орошение почвы, рекультивация засоленных земель, новые агротехнические методы и технологии [8].

Перечисленные проблемы особенно актуальны для Республики Ирак, основу экономического благополучия которой составляют нефть и сельское хозяйство. Земли сельскохозяйственного назначения составляют примерно пятую часть территории Ирака, из них половина расположена в долинах Евфрата и Тигра и 
относится к орошаемым угодьям [9]. До 1995 г. Ирак по площади орошаемых земель (3,5 млн га) входил в десятку ведущих стран мира. Основными орошаемыми культурами являются хлопок, овощи, фрукты и зерновые культуры $[9,10]$.

До середины 90-х гг. доля сельского хозяйства в валовом национальном продукте Ирака составляла 7 \%, происходил рост посевных площадей, были построены крупные плотины и ирригационные системы, восстановлены старые каналы. После вторжения в Кувейт, в отношении Ирака была начата экономическая блокада и предотвращен импорт жизненно важных товаров. В результате военной операции США и её стран-союзников против Ирака в 2003 г. были разрушены основные оросительные и дренажные системы [5]. Фермеры стали продавать скот, сокращать площади обрабатываемых земель и использовать низкокачественные удобрения. Переход рабочей силы в государственный сектор, миграция населения в города, отсутствие государственных субсидий, многолетняя сильная засуха (2004-2010 гг.) нанесли значительный ущерб сельскому хозяйству [9], его производительность упала на 90 \%. Последствия засухи были усилены экономическими санкциями против Ирака, запретившими импорт с.-х. товаров, включая технику и удобрения. Ситуацию осложнили межобщинные столкновения, вынуждающие жителей временно покидать свои деревни и земельные угодья.

К положительным моментам можно отнести деятельность Международного комитета Красного Креста, за счет которого в последние годы в провинциях Центрального Ирака (Дияла, Багдад, Васит и Бабиль) установлены системы капельного орошения [11]. Они позволяют экономить расход воды на 67 \% и значительно снижают риск потери урожая в условиях сильной засухи.

Для максимально эффективного ведения сельскохозяйственного производства в экстремальных условиях природного и антропогенного характера необходима объективная информация о территориальновременной изменчивости состояния растительности. Современный мониторинг земель в значительной меpe основан на геоинформационных технологиях и результатах дистанционного зондирования Земли [12-16]. Использование разновременных данных позволяет оценивать происходящие процессы по обнаруженным различиям в состоянии объектов [17-21]. Например, в работе [22] путем анализа изображений, полученных со спутника Landsat-5, выявлены изменения в классах растительности г. Халабджа (Ирак), обстрелянного химическим оружием 16 марта 1988 г. Установлено резкое снижение густой, разреженной и умеренной растительности на 55, 7 и $9 \%$ соответственно и рост площади пустынной территории на $5 \%$. В результате дистанционных исследований в провинции Багдад [23] в период с 1990 по 2001 гг. обнаружен рост площадей посадок с 44760 до 75411 га и сокращение площадей деградированных земель. В [24] установлены явные экологические изменения, произошедшие в растительном покрове болот Междуречья и юга Ирака в период с 1973 по 2004 гг., а именно, сокращение площади растительно- го покрова и поверхностных вод и рост площади бесплодных засушливых и заболоченных территорий.

Необходимость скорейшего восстановления разрушенного хозяйства и максимальной экономии средств в сложных природных и антропогенных условиях вызывают потребность в оперативном мониторинге состояния земель сельскохозяйственного назначения, сосредоточенных преимущественно в Центральном Ираке.

Независимо от причины, процесс деградации земель начинается с повреждения растительного покрова $[25,26]$, биомасса которого является наиболее динамичной характеристикой [27]. Для ее оценки используют различные вегетационные индексы, рассчитываемые по данным дистанционного зондирования Земли (Д33) [28, 29].

Целью исследования является анализ динамики состояния растительного покрова территорий четырех провинций Центрального Ирака с использованием нормализованного разностного вегетационного индекса NDVI в период с 2014 по 2017 гг.

\section{Объекты и методы исследований}

Объекты исследования

Республика Ирак находится на Ближнем Востоке, между Ираном и Саудовской Аравией, граничит на западе с Иорданией и Сирией, на юго-востоке - с Кувейтом, на севере - с Турцией (рис. 1, А) и занимает площадь 437072 кв. км [30, 31]. Климат на севере резко континентальный, на юге жаркий и сухой. Температура воздуха в регионах варьирует от $50-60{ }^{\circ} \mathrm{C}$ (июль, август) до нуля и ниже (январь). Максимум осадков выпадает с ноября по апрель (90 \%), поздней осенью и зимой дожди крайне редки, выпадают нерегулярно. Во время засух уровень воды в реках падает, снижается урожай, и возникают проблемы с питьевой водой. Снега практически нет. Характерны ветровые явления и пыльные бури [30-32].

Всю страну пересекают Тигр и Евфрат, самые полноводные реки Ближнего Востока, которые играют исключительную роль в хозяйстве Ирака. Их разливы зависят от таяния снегов на Армянском нагорье, они максимальны в феврале-мае и минимальны в сентябре и октябре [33]. Наиболее динамично развитие растений в Ираке происходит в начале года, что подтверждается максимальным диапазоном изменчивости значений NDVI [34]. Поэтому для анализа выбраны многолетние (февраль-март 2014-2017 гг.) ряды данных Д33 четыpex провинций: Багдад, Бабиль, Васит и Дияла, границы которых показаны на рис. 1, Б.

Изучаемые провинции находятся в пустыне, в зоне аридного климата. Среднегодовая температура воздуха составляет в Багдаде $22,8^{\circ} \mathrm{C}$, в Бабиле и Дияле $22,9^{\circ} \mathrm{C}$, в Васите $23^{\circ} \mathrm{C}$. Среднегодовое количество осадков в Багдаде - 156 мм, в Васите - 221 мм, в Дияле - 228 мм. В Бабиле осадки в течение года отсутствуют [35]. Главными сельскохозяйственными культурами в Багдаде являются рис, кукуруза, финики, хлопок, овощи и фрукты, в Бабиле - пшеница, ячмень и финики, в Дияле и Васите - фрукты и финики [9]. 


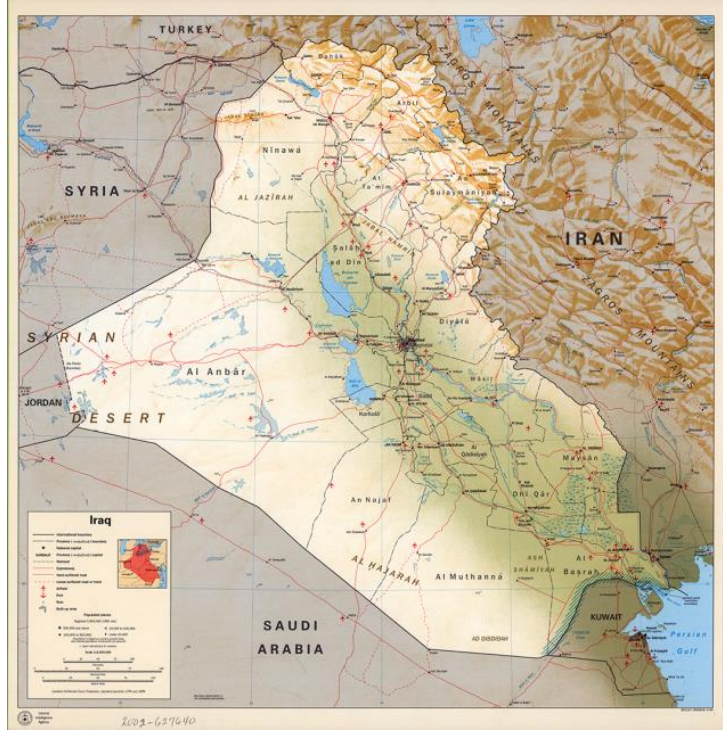

A

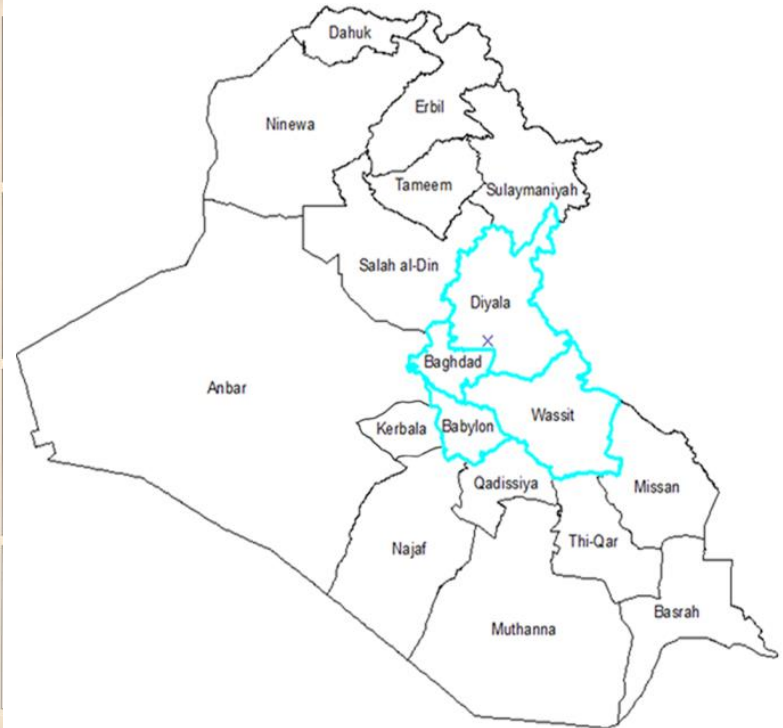

Б

Рис. 1. Карта Республики Ирак по [31] (А) и границы исследуемых провинций (Б)

Fig. 1. Map of the Republic of Iraq by [31] (A) and the boundaries of selected provinces for this study (B)

По данным метеостанций, территориально близких к изучаемым провинциям, погодные условия февраля-марта 2015-2017 гг. оказались сходными. Осадки отсутствовали. Наблюдались природные засухи в провинции Багдад в 2015 и 2017 гг., а также в провинции Дияла в 2015 г. [36].

\section{Методы исследования}

Как было указано выше, для оценки распределения растительного покрова и состояния растительности и почвы используются различные вегетационные индексы, рассчитываемые по данным Д33 [28, 29]. Вегетационный индекс представляет собой числовое значение, которое определяют для каждого пикселя аэрокосмического снимка земной поверхности на основе комбинации данных, полученных при съемке в разных диапазонах электромагнитного спектра. В данной работе использовался известный вегетационный индекс NDVI [37], который является показателем состояния экосистемы и часто коррелирует со следующими параметрами: продуктивность и биомасса растительности; влажность, температура, испаряемость и минеральная или органическая насыщенность почвы; объем выпадаемых осадков и др. Зависимость между этими параметрами и значениями NDVI, как правило, не прямая и обусловлена особенностями исследуемой территории, ее климатическими и экологическими характеристиками [38]. NDVI позволяет дать количественную оценку фотосинтетически активной биомассы и, соответственно, плотности растительности на заданном участке территории. Его рассчитывают по формуле [37]:

$$
N D V I=\frac{\rho_{\text {nir }}-\rho_{\text {red }}}{\rho_{\text {nir }}+\rho_{\text {red }}},
$$

где $\rho_{\text {nir }}$ - значения спектральной яркости пикселя в ближнем инфракрасном диапазоне; $\rho_{\text {red }}-$ в красном диапазоне электромагнитного спектра, по данным, получа- емым с различных спутников [39, 40]. NDVI применяется для широкого спектра исследований $[22,23,25,34,41$, 42], в том числе в сельском и лесном хозяйстве.

В работе для расчета NDVI использованы данные co спутника Landsat-8 (сканер OLI), являющегося современным средством мониторинга состояния растительного покрова в региональном масштабе [43-50]. Они имеют пространственное разрешение 30 м в видимом и инфракрасном диапазонах электромагнитного спектра и периодичность съемки 16 дней, доступны на сайте Геологической службы США [51] и распространяются на безвозмездной основе.

Полученные космические снимки соответствовали уровню обработки LT1, и каждый пиксель изображения был представлен калиброванным значением яркости Digital Number (DN). Для получения корректных значений NDVI и проведения анализа по космическим снимкам с разными датами съемки значения DN были конвертированы в значения спектральной яркости на земной поверхности по формулам, предлагаемым в руководстве Handbook Landsat 8 [52].

Далее для каждого космического снимка были рассчитаны значения NDVI. Для зонирования территории по плотности растительности была проведена классификация данных полученных карт NDVI с использованием метода параллелепипеда [53]. Значения границ классов задавались в соответствии со значениями NDVI и плотностью растительности по следующей классификации: нет растительности (-1-0), слабая растительность $(0-0,15)$, умеренной плотности $(0,15-0,30)$, плотная $(0,30-0,45)$, очень плотная $(0,45-0,60)$, максимальной плотности $(0,6-1,0)$ (рис. 2).

Анализ динамики состояния растительного покрова изучаемых территорий проводился по снимкам, полученным в близкие даты февраля и марта в период с 2014 по 2017 гг. (19.02.2014; 23.03.2014; 06.02.2015; 09.02.2016; 12.03.2016; 11.02.2017; 15.03.2017) (рис. 3). Координаты снимков в системе WRS2 - path 168, row 37. 
Известия Томского политехнического университета. Инжиниринг георесурсов. 2020. Т. 331. № 6. 19-31 Токарева О.С. и др. Мониторинг состояния растительного покрова территории Центрального Ирака с использованием ...

\begin{tabular}{|c|c|c|c|c|c|c|}
\hline $\begin{array}{l}\text { Классификация } \\
\text { растительности } \\
\text { / Vegetation } \\
\text { classification }\end{array}$ & $\begin{array}{c}\text { Нет } \\
\text { растительности } \\
\text { / No vegetation }\end{array}$ & $\begin{array}{l}\text { Слабая } \\
\text { / Poor }\end{array}$ & $\begin{array}{l}\text { Умеренная } \\
\text { / Moderate }\end{array}$ & $\begin{array}{l}\text { Плотная } \\
\text { / Dense }\end{array}$ & $\begin{array}{c}\text { Очень } \\
\text { плотная } \\
\text { / Very dense }\end{array}$ & $\begin{array}{c}\text { Максимальной } \\
\text { плотности } \\
\text { / High }\end{array}$ \\
\hline $\begin{array}{l}\text { Значение NDVI } \\
\text { / NDVI value }\end{array}$ & $-1-0$ & $0-0,15$ & $0,15-0,30$ & $0,30-0,45$ & $0,45-0,60$ & $0,6-1,0$ \\
\hline Изображение & & & & & & \\
\hline
\end{tabular}

Pис. 2. Классификация растительности, используемая в статье

Fig. 2. Vegetation classification used in the article

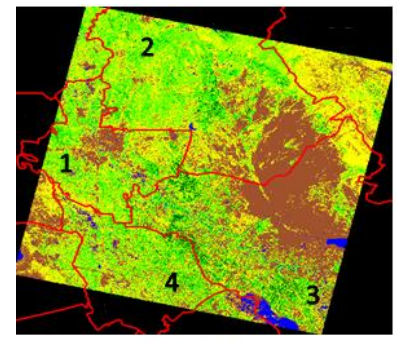

19.02.2014

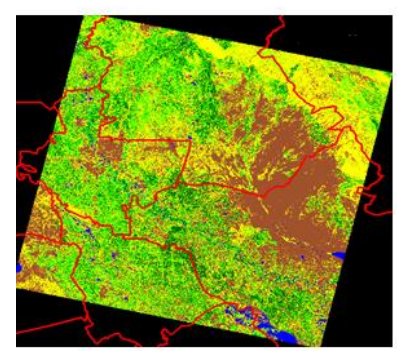

23.03.2014

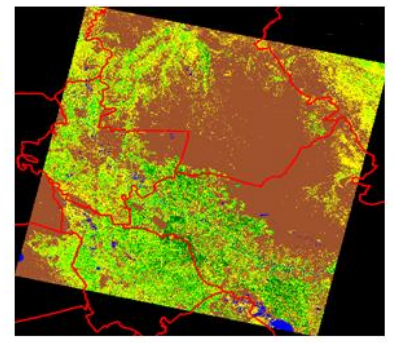

06.02.2015

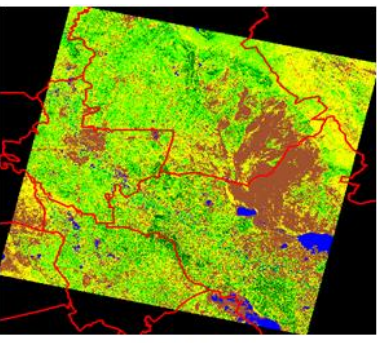

09.02.2016

A

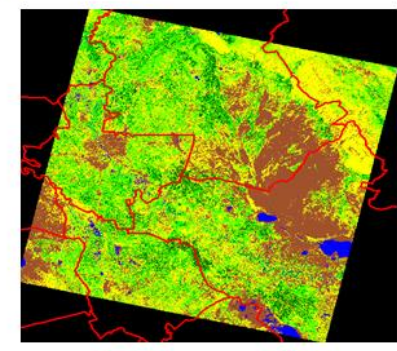

12.03 .2016

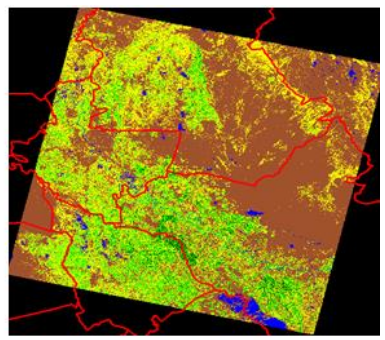

11.02.2017

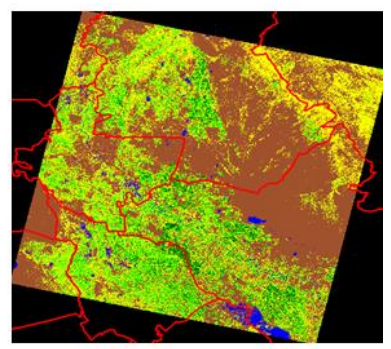

15.03.2017

B

Нет растительности / No vegetation Слабая растительность / Poor vegetation Умеренная растительность / Moderate vegetation

$\square$ Плотная растительность / Dense vegetation

Очень плотная растительность/Very dense vegetation

Растительность максимальной плотности / High vegetation

Pис. 3. Карты классификации NDVI по годам в феврале (A) и марте (В) 2014-2017 г2. провиниий: 1) Багдад, 2) Дияла, 3) Васит, 4) Бабиль

Fig. 3. NDVI classification maps by year in February (A) and March (B) 2014-2017 of provinces: 1) Baghdad, 2) Diyala, 3) Wasit, 4) Babil

Далее были рассчитаны площади, занимаемые растительностью каждого класса, построены графики изменения площадей классов во времени (по годам), и проведен анализ изменения соотношения площадей классов растительности в каждом регионе за 2014-2017 гг. Полученные данные обработаны с применением методов корреляционного анализа и вариационной статистики.

Для объяснения полученных закономерностей рассчитаны среднесуточные температуры воздуха (по данным [36]). Использованы данные метеостанций, территориально близких к изучаемым провинциям. Отмечены природные засухи в провинции Багдад и близлежащих территориях в 2015 и 2017 гг., в провинции Дияла в 2015 г. Среднесуточная температура в 2016-2017 гг. в провинциях составила 12.03.2016$18,4{ }^{\circ} \mathrm{C}, 11.02 .2017-10,3{ }^{\circ} \mathrm{C} ; 15.03 .2017-19,0{ }^{\circ} \mathrm{C}$ (даты выбраны в соответствии с рис. 3). Осадки в указанные периоды отсутствовали. Рассчитаны коэффи- циенты корреляции между температурными данными и значениями NDVI, а также коэффициенты вариации значений NDVI. Число данных в выборке составило 168 , точность расчетов $95 \%$.

Для обработки и представления данных использовано программное обеспечение QGIS [54] и ERDAS Imagine [55].

\section{Результаты и обсуждение}

Анализ значений NDVI выявил региональные особенности развития растительности на территориях провинций Центрального Ирака в начале полевых работ (рис. 4).

Изменение площадей составило на территориях:

- не покрытых растительностью - 30,81-169,83 км² (Дияла; 12.03 .16 - Васит; 09.02.16, соответственно); отношение минимума к максимуму (Max/Min) $-5,5$;

- покрытых слабой растительностью - 460,99-6452,17 км² (Бабиль, 12.03.16 - Дияла; 11.02.17); Max/Min=14,0; 
- покрытых умеренной растительностью 856,34-3032,34 км² (Бабиль, 23.03.14 - Дияла; 09.02.16); $\mathrm{Max} / \mathrm{Min}=3,5$;

- покрытых плотной растительностью - 441,47-2725 км² (Дияла, 06.02.15 - Дияла, 19.02.14); Max/Min=6,2

- покрытых очень плотной растительностью 223,64-1622,84 км² (Дияла, 06.02.15 - Дияла, 09.02.16); $\mathrm{Max} / \mathrm{Min}=7,3$

- покрытых растительностью максимальной плотности - 80,63-1051,04 км² (Багдад, 11.02.17 - Дияла, 23.03.14); Max/Min=13,0.

Максимальные площади земель, не покрытых растительностью, обнаружены в Багдаде и Васите; покрытых растительностью большинства классов также в Васите; покрытых плотной растительностью - в Дияле, отмеченной также минимумом бесплодных территорий. Бабиль отличается наимень- шей площадью, покрытой растительностью. Багдад по изученным показателям занимает промежуточное положение. При равномерном распределении растительности в самой маленькой провинции (Багдад) можно было бы ожидать соответствующий минимум площадей, покрытых растительностью всех классов; в самой крупной провинции Дияла их максимум. Реальная картина указывает на наличие явных неоднородностей в распределении растительности.

Особенности развития растительного покрова провинций Центрального Ирака. Во время периода активной вегетации для всех провинций выявлена стабильность значений площади территорий без растительности (0-4\%), а также закономерный рост площадей территорий с растительностью средней плотности (17-35 \%) (рис. 4, 5).
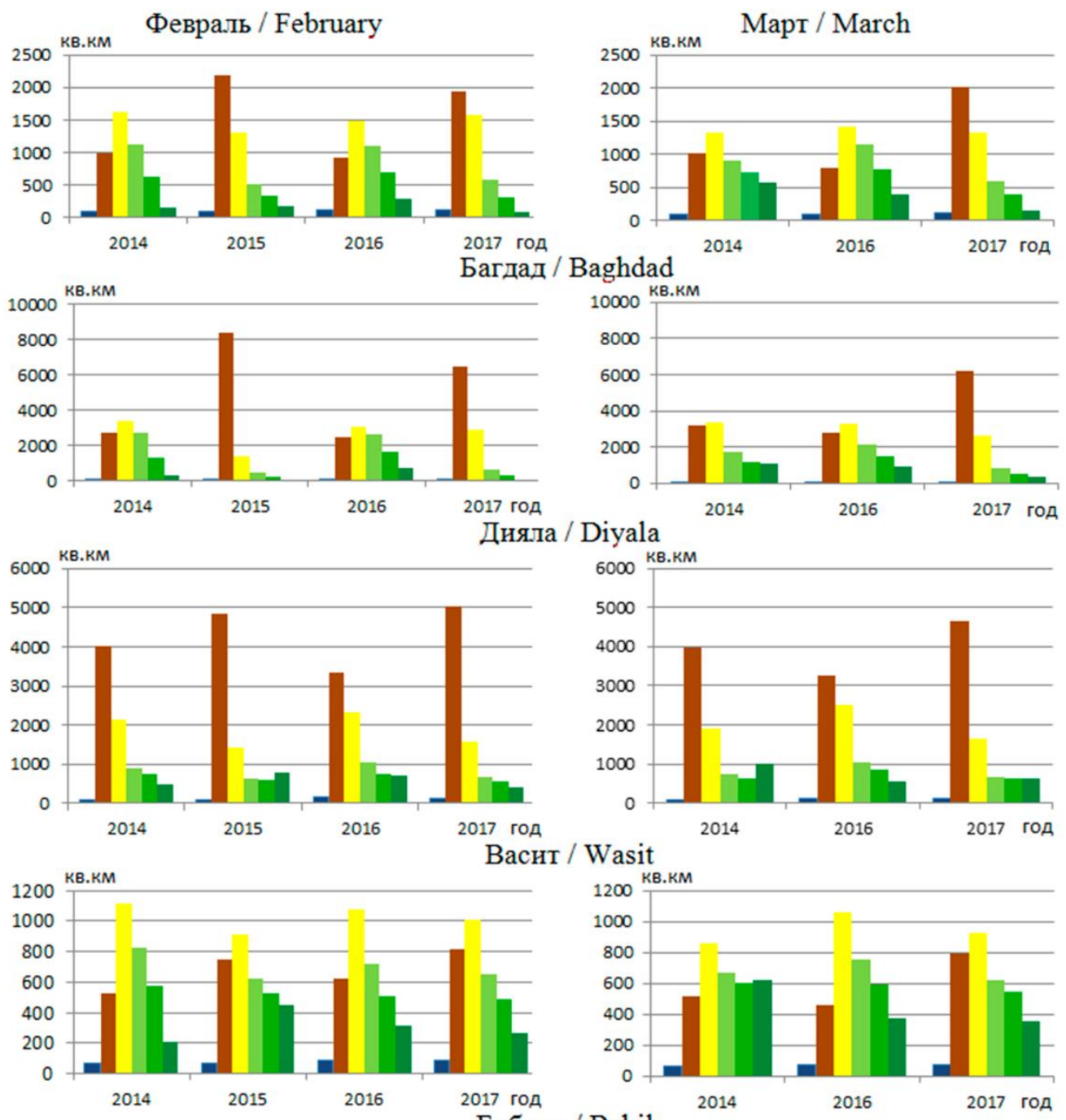

Нет растительности / No vegetation

Слабая растительность / Poor vegetation

Умеренная растительность / Moderate vegetation

\section{Бабнль / Babil}

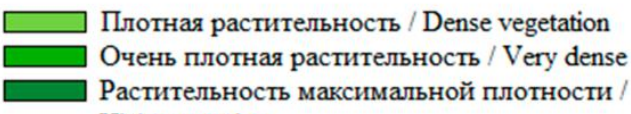
High vegetation

Рис. 4. Территориально-временная изменчивость значений NDVI

Fig. 4. Territorial-temporal variability of NDVI values 


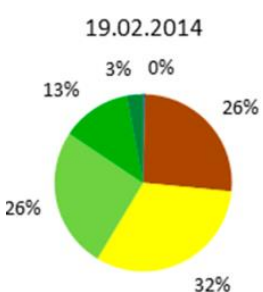

23.03.2014

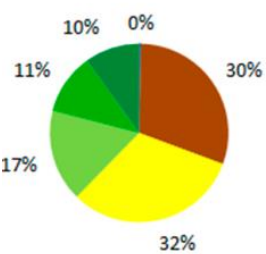

19.02.2014

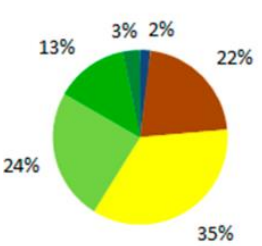

23.02.2014

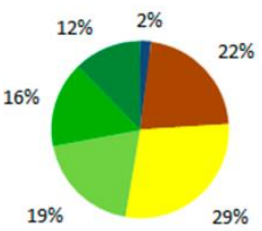

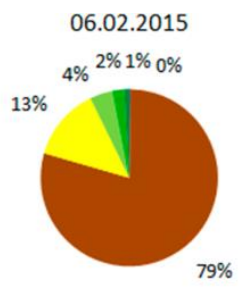

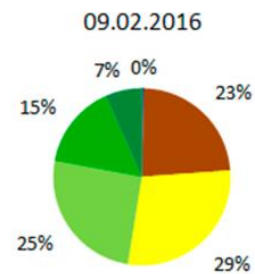

12.03.2016

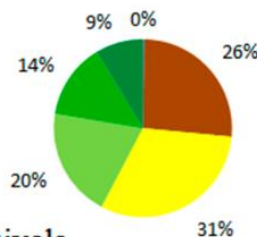

Дияла / Diyala
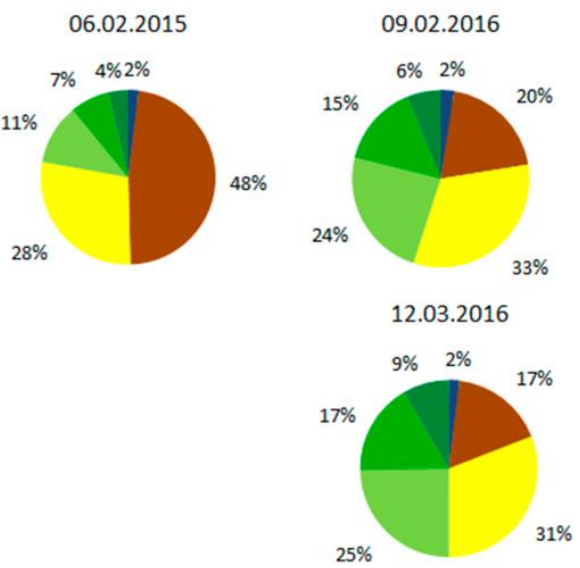

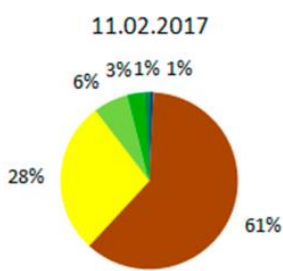

15.03.2017

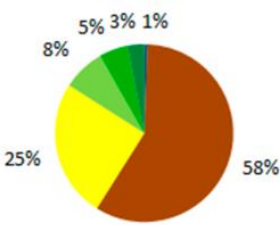

11.02 .2017

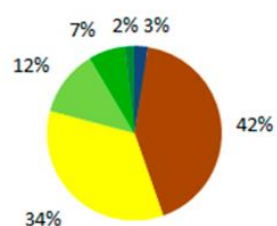

15.03.2017

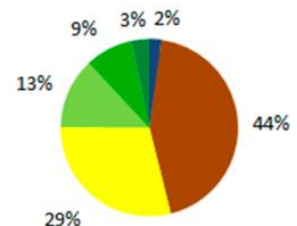

Багдад / Baghdad

Рис. 5. Структура растительности в провинциях Дияла и Багдад в феврале-марте 2014-2017 г2. (легенда в соответствии с рис. 4)

Fig. 5. Vegetation structure in Diyala and Baghdad provinces in February-March 2014-2017

Соотношение других площадей меняется по годам разнонаправленно и с разной скоростью. В Багдаде с февраля по март доля площадей со слабой и плотной растительностью возрастает более чем в 2 раза (20$48 \%$ и $11-24 \%$ соответственно), а доля площадей с очень плотной растительностью изменяется незначительно (7-15\%). Обращает на себя внимание рост доли площадей с очень плотной растительностью в четыре раза, что обусловлено усилением вегетации сельскохозяйственных культур.

Близкая картина перераспределения площадей с растительностью разных классов характерна для провинции Васит: отсутствие растительности на площадях в 1-2 \%; преобладание площадей со слабой растительностью (39-60\%); стабильность площадей с плотной, очень плотной и растительностью высокой плотности (6-13\%).

Кербела отличается очень высокой долей площадей со слабой растительностью (23-79\% в феврале и $30-58 \%$ в марте), заметным ростом доли площадей с плотной растительностью (4-26\% в феврале и 8-20\% в марте) и с очень плотной растительностью (1-15\% и 5-14\%). Доля площадей с растительностью высокой плотностью меняется от 1 до $7 \%$ в феврале и $10 \%$ в марте.
Бабиль характеризуется заметно иной структурой площадей, занятых растительностью, и их относительной стабильностью. Территории со слабой и плотной растительностью занимают 15-25 \% площади в феврале-марте, с очень плотной растительностью - 15-18\%, с растительностью высокой плотности - 6-13\% в феврале и 11-19\% в марте.

Анализ площадей разных групп растительности по провинциям выявил их незначительную и среднюю многолетнюю изменчивость для Бабиля и Диялы, среднюю для провинции Васит, незначительную, среднюю и значительную для провинции Багдад. Установлена высокая изменчивость площадей, слабо покрытых растительностью, - коэффициенты их вариации изменялись от 8 до 83 (таблица). Максимальная стабильность коэффициентов вариации (далее CV) установлена для площадей, покрытых умеренной растительностью $(<33)$.

Также выявлена разногодичная изменчивость площадей с разными классами растительности. В феврале-марте 2014 г. вариативность площадей территорий, не покрытых растительностью или покрытых слабой растительностью, изменялась в пределах 6-32 и 67-68 соответственно; площадей, покрытых умеренной и очень плотной растительностью 19-52 и 7-30. CV площадей, покрытых растительно- 
стью максимальной плотности, упала на 33 единицы. В 2015 г. показатели CV площадей, не покрытых или слабо покрытых растительностью, оказались выше, чем в 2014 г.; в 2016 г. - близкими по площадям, не покрытым растительностью, но ниже по площадям, покрытым слабой, очень плотной и растительностью максимальной плотности (в 4,5, 1,5 и 1,7 раза, соответственно). По площадям, занятым плотной растительностью, отмечено слабое падение CV, очень плотной растительностью - рост в 3 раза. В февралемарте 2017 г. показатели коэффициентов вариации значений NDVI по не покрытым растительностью или слабо покрытым территориям возросли, по покрытым умеренной растительностью и очень плотной растительностью выровнялись. Минимальной оказалась разногодичная изменчивость CV площадей территорий, покрытых умеренной растительностью, максимальной - слабой растительностью. CV площадей остальных территорий, покрытых растительностью других классов, оказались близкими по значениям.

Таблица. Вариативность значений площзадей по классам растительности, годам и месячам

Table. Variability of areas with vegetation classes, years and months

\begin{tabular}{|c|c|c|c|c|c|c|c|}
\hline 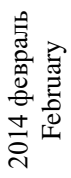 & 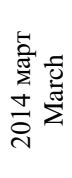 & 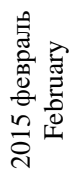 & 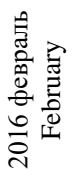 & 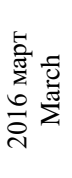 & 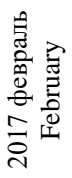 & 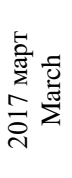 & 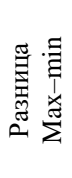 \\
\hline \multicolumn{8}{|c|}{ Отсутствие растительности/No vegetation } \\
\hline 6 & 32 & 58 & 21 & 25 & 18 & 25 & 40 \\
\hline \multicolumn{8}{|c|}{ Слабая растительность/Poor vegetation } \\
\hline 67 & 68 & 83 & 60 & 8 & 62 & 52 & 75 \\
\hline \multicolumn{8}{|c|}{ Умеренная растительность/Moderate vegetation } \\
\hline 19 & 52 & 17 & 42 & 27 & 39 & 31 & 33 \\
\hline \multicolumn{8}{|c|}{ Плотная растительность/Dense vegetation } \\
\hline 13 & 55 & 56 & 40 & 32 & 7 & 11 & 49 \\
\hline \multicolumn{8}{|c|}{ Очень плотная растительность/Very dense vegetation } \\
\hline 7 & 30 & 54 & 15 & 57 & 16 & 13 & 50 \\
\hline \multicolumn{8}{|c|}{ Растительность максимальной плотности/High vegetation } \\
\hline 57 & 24 & 70 & 70 & 40 & 31 & 30 & 46 \\
\hline
\end{tabular}

Отмечены следующие закономерности изменения $\mathrm{CV}$ - при переходе от февраля к марту вариации площадей, не занятых растительностью, занятых умеренной и плотной растительностью, стабильны; происходит рост вариации площадей с очень плотной и падение площадей со слабой растительностью и растительностью максимальной плотности. Корреляционный анализ между показателями NDVI и погодными условиями достоверных связей не выявил.

Полученные результаты можно интерпретировать следующим образом.

Условия перехода между соседними классами определяют его скорость и пороговые значения. Участки, на которых растительность отсутствует, полностью непригодны для сельскохозяйственного производства с силу объективных причин (горы, перепады высот, отсутствие источников водоснабжения и др.), поэтому их площадь сохраняется стабильной во времени и пространстве. Плотная растительность разных степеней развивается на территориях, занятых растительностью предыдущих классов (умеренная и слабая), поэтому рост ее площади максимален. Изменчивость площадей остальных классов растительности относительно равномерная.

Незначительная и средняя изменчивость площадей разных классов растительности в Бабиле и Дияле, средняя изменчивость в Васите, незначительная, средняя и значительная в Багдаде обусловлены, прежде всего, набором культур, сроками и темпами их вегетации. В Бабиле и Дияле культивируют преимущественно многолетние растения: в Бабиле кормовые культуры на пастбищах, в Дияле - финиковые пальмы и фруктовые деревья в садах. Специализация Багдада традиционно связана с выращиванием зерновых культур на пашне. Сельскохозяйственная специализация регионов хорошо объясняет выявленные закономерности. Многолетним плодовым культурам свойственно постепенное нарастание и сохранение биомассы, однолетним зерновым - ее резкое изменение в зависимости от стадии вегетации (посев - всходы - вегетативный рост и т. д.). Этим, в частности, объясняется максимальная доля территории Диялы, покрытая растительностью разной плотности. Кроме того, в провинции сельскохозяйственные угодья близки к двум главным рекам Ирака, имеется обширная сеть ирригационных сооружений, а культуры выращивают в несколько ярусов, к примеру, ананасы и фрукты в рощах финиковых пальм.

Близкий по срокам посев зерновых культур в разных провинциях и их интенсивное параллельное развитие объясняет существенное преимущество временной изменчивости площадей с растительностью разных классов перед территориальной.

Несомненно, большую роль в выращивании сельскохозяйственных растений, основного фактора изменения площади занятой растительностью, играют социально-экономические условия. Получение объективной информации о них затруднено в связи со сложными политическими событиями, частым отключением Интернета в Ираке, отсутствием справочной литературы. Экстремисты из террористической группировки «Исламское государство», запрещенной в России, нередко опускали шлюзы дамбы на реках, лишая крестьян возможности полива угодий и выработки электроэнергии (постоянное электричество отсутствует).

По данным одного из авторов данной публикации, гражданина Республики Ирак, антропогенными факторами снижения площадей под сельхозкультурами являются отсутствие удобрений, высокая цена семян, иностранный импорт продукции, отсутствие государственной поддержки, военные разрушения населенных пунктов. В Васите ситуация осложняется дефицитом водных ресурсов, в том числе в связи с неуклонным падением уровня воды в реке Евфрат, отдаленностью сел от источников водоснабжения, отсутствием в провинции постоянного электричества. Причинами сокращения площадей сельскохозяйственных угодий в Бабиле является полное отсутствие дождя, пыльные бури, чрезмерный выпас скота, а также миграция населения из сельской местности в города. 
Следует отметить, что выявленные значительные изменения в площадях и структуре растительного покрова свидетельствуют о потерях сельскохозяйственных земель и нарушении экологической ситуации в регионе. Мониторинг скорости и степени этих процессов методами дистанционного зондирования Земли позволяет получать важную информацию для анализа этих процессов и предотвращения неблагоприятного развития событий.

\section{Выводы}

1. С помощью вегетационных индексов, рассчитанных по данным Д3З, выявлены закономерности временно-территориальной динамики площадей разных классов растительности территории Центрального Ирака. Установлены региональные особенности, проявившиеся в структуре растительности и скорости ее изменения.

2. Максимальные площади земель, не покрытых растительностью, выявлены в Багдаде и Васите; покрытых растительностью большинства классовтакже в Васите; покрытых плотной растительностью - в Дияле, отмеченной также минимумом

\section{СПИСОК ЛИТЕРАТУРЫ}

1. Pushpam Kumar. The Economics of land degradation in Africa Benefits of action outweigh the costs: a report of ELD Initiative. Bonn: Kippconcept GmbH, 2015. - 156 p.

2. Proxy global assessment of land degradation / Z.G. Bai, D.L. Dent, L. Olsson, M.E. Schaepman // Soil Use and Management. - 2008 - V. 24. - № 3. - P. 223-234.

3. The issues of weed infestation with environmentally hazardous plants and methods of their control / V.L. Bogdanov, O.A. Pasko, V.F. Kovyazin, T.S. Posternak // IOP Conference Series: Earth and Environmental Science. - 2016. - V. 43. - № 1. - 012036. URL: https://iopscience.iop.org/article/10.1088/1755-

1315/43/1/012036/pdf (дата обращения: 01.02.2019).

4. Pomelov A.S., Pasko O.A., Baranova A.V. Comparative analysis of land management in the World // IOP Conference Series: Earth and Environmental Science. - 2015. - V. 27. - № 1. - 012040. URL: https://iopscience.iop.org/article/10.1088/1755-1315/27/1/012040/pdf (дата обращения: 01.02.2019).

5. Iraqi Agriculture in Crisis. 2017. URL: https://www.epicusa.org/agriculture-crisis/ (дата обращения: 01.02.2019).

6. Governance and the capacity to manage resilience in regiona socio-ecological systems / L. Lebel, J.M. Anderies, B. Campbell, C. Folke, S. Hattfield-Dodds, T.P. Hughes, J. Wilson // Ecology and Society. - 2006. - V. 11. - № 1. - Article number 19.

7. Abdelfattah M.A., Shahid S.A. A comparative characterization and classification of soils in Abu Dhabi Coastal Area in relation to arid and semi-arid conditions using USDA and FAO Soil classification systems // Arid Land Research and Management. - 2007. - V. 21. - № 3. - P. 245-271.

8. Lal R., Stewart B.A. World soil resources and food security (advances in soil sciences). - Boca Raton: CRC Press, 2011. $574 \mathrm{p}$.

9. Agriculture in Iraq: resources, potentials, constraints, and research needs and priorities. URL: http://www.ars.usda.gov/SP2UserFiles/ Place/50600000/Products-Reprints/2002/1107.pdf (дата обращения: 01.02.2019).

10. Monitoring-based analysis of agriculture in Iraq / O. Tokareva, O. Pasko, A. Alshaibi, M. Mochalov // IOP Conference Series: Earth and Environmental Science. - 2016. - V. 43. - № 1. - 012035. URL: https://iopscience.iop.org/article/10.1088/1755-1315/43/1/012035/pdf (дата обращения: 01.02.2019).

11. Ирак: жители сельских районов остаются в крайне сложном положении. URL: https://www.icrc.org/rus/resources/documents/ update/2011/iraq-update-2011-12-14.htm (дата обращения: 01.02.2019). бесплодных территорий. Бабиль характеризуется минимальной площадью, покрытой растительностью. Багдад по изученным показателям занимает промежуточное положение. Данные закономерности слабо согласуются с абсолютными значениями площадей провинций. Они вызваны сложившимися условиями хозяйствования и проявляются в качественной и количественной неоднородности распределения растительности по провинциям.

3. Во время активной стадии вегетации, при переходе от февраля к марту, вариации площадей, не занятых растительностью, занятых умеренной и плотной растительностью стабильны; в то же время происходит рост вариации площадей с очень плотной и падение площадей со слабой растительностью и растительностью максимальной плотности.

4. Корреляционный анализ между показателями NDVI и погодными условиями достоверных связей не выявил.

Работа выполнена в Томском политехническом университете в рамках программы повышения конкурентоспособности Томского политехнического университета.

12. Возможности дистанционной оценки состояния и степени деградации природных кормовых угодий / Ф.В. Ерошенко, С.А. Барталев, Н.Г. Лапенко, Е.В. Самофал, И.Г. Сторчак // Современные проблемы дистанционного зондирования Земли из космоса. - 2018. - Т. 15. - № 7. - С. 53-66.

13. Катаев М.Ю., Скугарев А.А., Сорокин И.Б. Возможности космического мониторинга для целей сельского хозяйства Томской области // Доклады ТУСУР. - 2017. - Т. 20. - № 3. С. $186-190$.

14. Михайленко И.М., Тимошин В.Н. Оценивание химического состояния почвенной среды по данным дистанционного зондирования Земли // Современные проблемы дистанционного зондирования Земли из космоса. - 2018. - Т. 15. - № 7. C. $102-113$.

15. Geoinformation systems for regional environmental studies / Y. Polichtchouk, E. Kozin, V. Ryuhko, O. Tokareva // Proceedings of SPIE - The International Society for Optical Engineering. 1999. - V. 3983. - P. 572-577.

16. Марков Н.Г. Геоинформационные системы предприятий нефтегазовой отрасли: функциональность, архитектура и перспективы развития // Известия Томского политехнического университета. Инжиниринг георесурсов. - 2017. - Т. 328. № 9. - C. 16-32

17. Landscape disturbance caused by non-renewable energy production in a semi-arid region: a case study on the Russian steppe / K.V. Mjachina, C.W. Baynard, A.A. Chibilyev, R.D. Richardson // International Journal of Sustainable Development and World Ecology. - 2018. - V. 25. - № 6. P. 541-553.

18. Плотников Д. Е., Хвостиков С. А., Барталев С. А. Метод автоматического распознавания сельскохозяйственных культур на основе спутниковых данных и имитационной модели развития растений // Современные проблемы дистанционного зондирования Земли из космоса. - 2018. - Т. 15. - № 4. - С. 131-141.

19. The possibility of distance methods application for snow dump sites monitoring / O. Pasko, E. Makartsova, N. Ushakova, O. Tokareva, M. Mochalov // MATEC Web of Conferences. 2016. - V. 48. - 05002. URL: https://doi.org/10.1051/matecconf/ 20164805002 (дата обращения: 01.02.2019).

20. Kovalev A., Tokareva O. Using MODIS NDVI products for vegetation state monitoring on the oil production territory in Western Siberia // MATEC Web of Conferences. - 2016. - V. 48. 05003. URL: https://doi.org/10.1051/matecconf/20164805003 (дата обращения: 01.02.2019). 
21. Ziboon A.R.T., Alawan I.A., Khalaf A.G. Study and analysis of desertification phenomenomen in Karbala governorate by remote sensing data and GIS // Iraqi Bulletin of Geology and Mining. 2015 - V. 11 - № 1. - P. 143-156.

22. Al-doski J., Mansor S.B., Shafri H.Z.M. NDVI differencing and post-classification to detect vegetation changes in Halabja City, Iraq // IOSR Journal of Applied Geology and Geophysics (IOSRJAGG). - 2013. - V. 1. - № 2. - P. 1-10.

23. Najeeb A.A. Estimation of the normalized Difference Vegetation Index (NDVI) variation for selected regions in Iraq for two years 1990\&2001 // Journal of University of Anbar for pure science. 2009. - V. 3. - № 3. - P. 86-89.

24. Saleh S.A.H. Studying of the environmental changes in marsh area using Landsat satellite images // Journal of Asian Scientific Research. - 2012. - V. 2. - № 8. - P. 427-435.

25. Assessing the effects of human-induced land degradation in the former homelands of northern South Africa with a $1 \mathrm{~km}$ AVHRR NDVI time-series / K.J. Wessels, S.D. Princ, P.E. Frost, D. van Zyl // Remote Sensing of Environment. - 2004. - V. 91. - № 1. P. 47-67.

26. Комплексная оценка развития деградации растительного покрова снежных отвалов / О.С. Токарева, О.А. Пасько, Н.С. Ушакова, Е.С. Макарцова, Л.А. Федорова // Современные проблемы дистанционного зондирования Земли из космоca. - 2018. - T. 15. - № 2. - C. 75-83.

27. Le Q.B., Nkonya E.M., Mirzabaev A. Biomass productivity-based mapping of global land degradation hotspots // Economics of land degradation and improvement - a global assessment for sustainable development / Eds. E. Nkonya, A. Mirzabaev, J. von Braun. - Cham: Springer, 2015. - P. 55-84.

28. Zhou G., Liu X., Liu M. Assimilating remote sensing phenological information into the WOFOST model for rice growth simulation // Remote Sensing. - 2019. - V. 11. - № 3. - 268. URL https://doi.org/10.3390/rs11030268 (дата обращения 01.02.2019).

29. Padmanaban R., Bhowmik A.K., Cabral P. Satellite image fusion to detect changing surface permeability and emerging urban heat islands in a fast-growing city // PLOS ONE. - 2019. - V. 14. - № 1. e0208949. URL: https://doi.org/10.1371/journal.pone.0208949 (дата обращения 01.02.2019)

30. Карта Республики Ирак. URL: https://www.maps-of-theworld.ru/asia/iraq/large-scale-detailed-country-profile-map-ofiraq-1994 (дата обращения: 01.02.2019).

31. Nations encyclopedia. Iraq. URL: https://www.nationsencyclopedia com/economies/Asia-and-the-Pacific/Iraq.html (дата обращения: 01.02.2019).

32. Climate change knowledge portal. Average monthly temperature \& rainfall for Iraq from 1901-2015. URL: http://sdwebx. worldbank.org/climateportal/index.cfm?page=country_historical_c limate\&ThisCCode=IRQ (дата обращения: 01.02.2019).

33. Реки Ирака. URL: http://www.best-country.org/asia/iraq/water_source (дата обращения: 01.02.2019).

34. Estimation of protein content in rice crop and nitrogen content in rice leaves through regression analysis with NDVI derived from camera mounted radio-control helicopter / K. Arai, M. Sakashita, O. Shigetomi, Y. Miura // International Journal of Advanced Research in Artificial Intelligence. - 2014. - V. 3. - № 3. - P. 12-19.

35. Baghdad Climate \& Temperature. URL: http://www.baghdad. climatemps.com (дата обращения: 01.02.2019).

36. Погода и климат. URL: http://www.pogodaiklimat.ru/ weather.php?id $=40656 \&$ bday $=15 \&$ fday $=15 \&$ amonth $=3 \&$ ayear $=20$ (дата обращения: 01.02.2019).

37. Monitoring vegetation systems in the Great Plains with ERTS J.W. Rouse, R.H. Haas, J.A. Scheel, D.W. Deering // 3rd Earth Resource Technology Satellite (ERTS) Symposium. Proc. Conf. USA, Washington, 1973. - V. 1. - P. 309-317.

38. An extended AVHRR 8-km NDVI dataset compatible with MODIS and SPOT vegetation NDVI data / C.J. Tucker, J.E. Pinzon, M.E. Brown, D.A. Slayback, E.W. Pak, R. Mahoney, E.V. Vermote, N. El Saleous // International Journal of Remote Sensing. - 2005. - V. 26. - № 20. - P. 4485-4498.
39. Evaluation of the consistency of long-term NDVI time series derived from AVHRR, SPOT-vegetation, SeaWiFS, MODIS, and Landsat ETM+ sensors / M.E. Brown, J.E. Pinzón, K. Didan, J.T. Morisette, C.J. Tucker // IEEE Transactions on Geoscience and Remote Sensing. - 2006. - V. 44. - № 7. - P. 1787-1793.

40. Global evaluation of four AVHRR-NDVI data sets: Intercomparison and assessment against Landsat imagery / H.E. Beck, T.R. McVicar, A.I.J.M. van Dijk, J. Schellekens, R.A.M. de Jeu, L.A. Bruijnzeel // Remote Sensing of Environment. - 2011. - V. 115. - № 10. - P. 2547-2563.

41. Ahmad W.A., Ahmed M.A., Al-Sharia G.H. Using Normalized Difference Vegetation Index (NDVI) to identify hydrocarbon seepage in Kifl oil field and adjacent areas South of Iraq // Journal of Environment and Earth Science. - 2017. - V. 7. - № 1. - P. 16-30

42. Spring Normalized Difference Vegetation Index (NDVI) predicts annual variation in timing of peak faecal crude protein in mountain ungulates Steeve / S. Hamel, M. Garel, M. Festa-Bianchet, J.-M. Gaillard // Journal of applied ecology. - 2009. - V. 46. № 3. - P. 582-589.

43. Characterization of Landsat- 7 to Landsat- 8 reflective wavelength and 2 normalized difference vegetation index continuity / D.P. Roy, V. Kovalskyy, H.K. Zhang, E.F. Vermote, L. Yan, S.S. Kumar, A. Egorov // Remote Sensing of Environment. 2016. - V. 185. - P. 57-70.

44. Zhu Z., Woodcock C.E. Continuous change detection and classification of land cover using all available Landsat data // Remote Sensing of Environment. - 2014. - V. 144. - P. 152-171.

45. Kennedy R.E., Yang Z., Cohen W.B. Detecting trends in forest disturbance and recovery using yearly Landsat time series: 1 . LandTrendr - Temporal segmentation algorithms // Remote Sensing of Environment. - 2010. - V. 114. - № 12. - P. 2897-2910.

46. Monitoring conterminous United States (CONUS) land cover change with Web-Enabled Landsat Data (WELD) / M.C. Hansen, A.J. Egorov, P.V. Potapov, S.V. Stehman, A. Tyukavina, S.A. Turubanova, D.P. Roy, S.J. Goetz, T.R. Loveland, Ju.A. Kommareddy, V. Kovalskyy, C. Forsyth, T. Bents // Remote Sensing of Environment. - 2014. - V. 140. - P. 466-484.

47. Anderson L.O. Biome-scale forest properties in Amazonia based on field and satellite observations // Remote Sensing. - 2012. V. 4. - № 5. - P. 1245-1271.

48. Quantifying forest cover loss in Democratic Republic of the Congo, 2000-2010, with Landsat ETM+data / P.V. Potapov, S.A. Turubanova, M.C. Hansen, B. Adusei, M. Broich, A. Altstatt, L. Mane, C.O. Justice // Remote Sensing of Environment. 2012. - V. 122. - P. 106-116.

49. Mjachina K., Hu Z., Chibilyev A. Detection of damaged areas caused by the oil extraction in a steppe region using winter Landsat imagery // Journal of Applied Remote Sensing. - 2018. V. 12. - № 1. - 016017. URL: https://doi.org/10.1117/ 1.JRS.12.016017 (дата обращения: 01.02.2019).

50. Mapping cropping practices on a national scale using intra-annual landsat time series binning / P. Rufin, D. Frantz, S. Ernst, A. Rabe, P. Griffiths, M. Özdoğan, P. Hostert // Remote Sensing. - 2019. V. 11. - № 3. - 232. URL: https://doi.org/10.3390/rs11030232 (дата обращения: 01.02.2019).

51. Earth Explorer (Сайт Геологической службы CША). URL: https://earthexplorer.usgs.gov/ (дата обращения: 01.02.2019).

52. Zanter K. LANDSAT 8 (L8) Data users handbook. - Sioux Falls, South Dakota: EROS, 2016. - 98 p.

53. Al-doski J., Mansor S.B., Shafri H.Z.M. Image classification in remote sensing // Journal of Environment and Earth Science. 2013. - V. 3. - № 10. - P. 141-148.

54. QGIS. A free and open source geographic information system. URL: https://qgis.org/en/site/ (дата обращения: 01.02.2019).

55. ERDAS IMAGINE. URL: https://www.hexagongeospatial.com/ products/power-portfolio/erdas-imagine (дата обращения: 01.02.2019).

Поступила 02.12.2019 2. 


\section{Информация об авторах}

Toкарева O.C., кандидат технических наук, доцент отделения информационных технологий Инженерной школы информационных технологий и робототехники Национального исследовательского Томского политехнического университета.

Пасько О.А., доктор сельскохозяйственных наук, профессор отделения геологии Инженерной школы природных ресурсов Национального исследовательского Томского политехнического университета.

Маджид C.M., магистрант отделения информационных технологий Инженерной школы информационных технологий и робототехники Национального исследовательского Томского политехнического университета.

Кабраль П., доктор прикладной математики, доцент Школы информационного менеджмента Лиссабонского университета. 
UDC 332.234.4:631.1:528.8:55:002.6

\title{
MONITORING VEGETATION STATE IN THE CENTRAL IRAQ USING LANDSAT-8 SATELLITE DATA
}

\author{
Olga S. Tokareva1, \\ ost@tpu.ru
}

\section{Olga A. Pasko', oap@tpu.ru}

\author{
Saif M. Majid', \\ ostokareva@gmail.com
}

\author{
Pedro Cabral2, \\ pcabral@novaims.unl.pt \\ 1 National Research Tomsk Polytechnic University, \\ 30, Lenin avenue, Tomsk, 634050, Russia. \\ 2 Nova University of Lisbon, Nova Information Management School, \\ 1070-312, Lisboa, Portugal.
}

The relevance of the research is caused by the need to obtain objective information about the patterns of territorial and temporal variability of vegetation state and the factors that determine it for the most effective use of lands in extreme natural and socio-economic conditions in the Republic of Iraq.

The aim of the research is to analyze the dynamics of vegetation of territories of the four provinces in Central Iraq using the normalized difference vegetation index NDVI in the period from 2014 to 2017.

The objects of the research are territories of Central Iraq: Babil, Baghdad, Wasit and Diyala. The subject of the study is temporal-territorial variability of vegetation state.

Methods: remote sensing, thematic mapping, image processing, spatial data analysis, statistical analysis.

Results. Patterns of temporarily-territorial dynamics of vegetation state in Central Iraq were revealed using vegetation index NDVI calculated with remote sensing data obtained by Landsat-8. Regional features of the vegetation structure and the rate of its state change were established. The maximum areas of non-vegetated territories were found in Baghdad and Wasit; covered by vegetation of most classes - also in Wasit; covered by dense vegetation - in Diyala, marked as well by minimum of barren areas. Babil is characterized by minimum area covered by vegetation. Baghdad in the studied indicators is intermediate. These patterns are poorly consistent with the absolute values of the province areas. They are caused by the prevailing economic conditions and are manifested in the qualitative and quantitative heterogeneity of the distribution of vegetation in the provinces. During the active stage of vegetation, from February to March, the variations in areas of non-vegetated territories, occupied by moderate and dense vegetation, are stable. At the same time, the variability of areas of territories with very dense vegetation is growing, with weak vegetation and vegetation of maximum density decreases. A correlation analysis between NDVI values and weather conditions did not reveal any significant relationships.

\section{Key words:}

Vegetation index, geoinformation system, remote sensing data, vegetation classes, agriculture, Central Iraq.

The research is carried out at Tomsk Polytechnic University within the framework of Tomsk Polytechnic University Competitiveness Enhancement Program.

\section{REFERENCES}

1. Pushpam Kumar. The Economics of land degradation in Africa. Benefits of action outweigh the costs: a report of ELD Initiative. Bonn, Kippconcept GmbH, 2015. 156 p.

2. Bai Z.G., Dent D.L., Olsson L., Schaepman M.E. Proxy global assessment of land degradation. Soil Use and Management, 2008 vol. 24, no. 3, pp. 223-234.

3. Bogdanov V.L., Pasko O.A., Kovyazin V.F., Posternak T.S. The issues of weed infestation with environmentally hazardous plants and methods of their control. IOP Conference Series: Earth and Environmental Science, 2016, vol. 43, no 1, 012036. Available at: https://iopscience.iop.org/article/10.1088/1755-1315/43/1/012036/pdf (accessed 1 February 2019).

4. Pomelov A.S., Pasko O.A., Baranova A.V. Comparative analysis of land management in the World. IOP Conference Series: Earth and Environmental Science, 2015, vol. 27, no. 1, 012040. Available at: https://iopscience.iop.org/article/10.1088/1755-1315/27/1/012040/pdf (accessed 1 February 2019).
5. Iraqi agriculture in crisis. 2017. Available at: https://www.epicusa.org/agriculture-crisis/ (accessed 1 February 2019).

6. Lebel L., Anderies J.M., Campbell B., Folke C., Hattfield-Dodds S., Hughes T.P., Wilson J. Governance and the capacity to manage resilience in regional socio-ecological systems. Ecology and Society, 2006, vol. 11, no. 1, Article number 19. Available at: http://www.ecologyandsociety.org/vol11/iss1/art19/ (accessed 1 February 2019).

7. Abdelfattah M.A., Shahid S.A. A comparative characterization and classification of soils in Abu Dhabi Coastal Area in relation to arid and semi-arid conditions using USDA and FAO Soil classification systems. Arid Land Research and Management, 2007, vol. 21, no. 3, pp. 245-271.

8. Lal R., Stewart B.A. World soil resources and food security (advances in soil sciences). Boca Raton, CRC Press, 2011. 574 p.

9. Agriculture in Iraq: resources, potentials, constraints, and research needs and priorities. Available at: http://www.ars.usda.gov/ SP2UserFiles/Place/50600000/Products-Reprints/2002/1107.pdf (accessed 1 February 2019). 
10. Tokareva O., Pasko O., Alshaibi A., Mochalov M. Monitoringbased analysis of agriculture in Iraq. IOP Conference Series: Earth and Environmental Science, 2016, vol. 43, no. 1, 012035. Available at: https://iopscience.iop.org/article/10.1088/1755-1315/43/1/012035/pdf (accessed 1 February 2019).

11. Irak: zhiteli selskikh rayonov ostayutsya $v$ krayne slozhnom polozhenii [Iraq: residents of rural areas remain in an extremely difficult situation]. Available at: https://www.icrc.org/rus/ resources/documents/update/2011/iraq-update-2011-12-14.htm (accessed 1 February 2019).

12. Eroshenko F.V., Bartalev S.A., Lapenko N.G., Samofal E.V., Storchak I.G. Capabilities for rangelands state and degradation assessment using remote sensing data. Sovremennye problemy distantsionnogo zondirovaniya Zemli iz kosmosa, 2018, vol. 15, no. 7, pp. 53-66. In Rus.

13. Kataev M.Yu., Skugarev A.A., Sorokin I.B. Possibilities of space monitoring for agriculture in Tomsk region. Proceedings of TUSUR, 2017, vol. 20, no. 3, pp. 186-190. In Rus.

14. Mikhaylenko I.M., Timoshin V.N. Assessment of the chemical state of soil environment from remote sensing data of the Earth. Sovremennye problemy distantsionnogo zondirovaniya Zemli iz kosmosa, 2018, vol. 15, no. 7, pp. 102-113. In Rus.

15. Polichtchouk Y., Kozin E., Ryuhko V., Tokareva O. Geoinformation systems for regional environmental studies Proceedings of SPIE - The International Society for Optical Engineering, 1999, vol. 3983, pp. 572-577.

16. Markov N.G. Geoinformation systems for oil and gas enterprises: functionality, architecture and development prospects. Bulletin of the Tomsk Polytechnic University. Geo Assets Engineering, 2017, vol. 328, no. 9, pp. 16-32. In Rus.

17. Mjachina K.V., Baynard C.W., Chibilyev A.A., Richardson R.D. Landscape disturbance caused by non-renewable energy production in a semi-arid region: a case study on the Russian steppe. International Journal of Sustainable Development and World Ecology, 2018, vol. 25, no. 6, pp. 541-553.

18. Plotnikov D.E., Khvostikov S.A., Bartalev S.A. Method for automated crop types mapping using remote sensing data and a plant growth simulation model. Sovremennye problemy distantsionnogo zondirovaniya Zemli iz kosmosa, 2018, vol. 15, no. 4, pp. 131-141. In Rus.

19. Pasko O., Makartsova E., Ushakova N., Tokareva O., Mochalov M. The possibility of distance methods application for snow dump sites monitoring. MATEC Web of Conferences, 2016, vol. 48, 05002 Available at: https://doi.org/10.1051/matecconf/20164805002 (accessed 1 February 2019).

20. Kovalev A., Tokareva O. Using MODIS NDVI products for vegetation state monitoring on the oil production territory in Western Siberia. MATEC Web of Conferences, 2016, vol. 48, $05003 . \quad$ Available at: https://doi.org/10.1051/matecconf/20164805003 (accessed 1 February 2019).

21. Ziboon A.R.T., Alawan I.A., Khalaf A.G. Study and analysis of desertification phenomenomen in Karbala governorate by remote sensing data and GIS. Iraqi Bulletin of Geology and Mining, 2015, vol. 11, no. 1, pp. 143-156.

22. Al-doski J., Mansor S.B., Shafri H.Z.M. NDVI differencing and post-classification to detect vegetation changes in Halabja City, Iraq. IOSR Journal of Applied Geology and Geophysics (IOSR$J A G G$ ), 2013, vol. 1, no. 2, pp. 1-10.

23. Najeeb A.A. Estimation of the Normalized Difference Vegetation Index (NDVI) variation for selected regions in Iraq for two years 1990\&2001. Journal of University of Anbar for pure science, 2009, vol. 3, no. 3, pp. 86-89.

24. Saleh S.A.H. Studying of the environmental changes in marsh area using Landsat satellite images. Journal of Asian Scientific Research, 2012, vol. 2, no. 8, pp. 427-435.

25. Wessels K.J., Princ S.D., Frost P.E., van Zyl D. Assessing the effects of human-induced land degradation in the former homelands of northern South Africa with a $1 \mathrm{~km}$ AVHRR NDVI time-series. Remote Sensing of Environment, 2004, vol. 91, no. 1, pp. 47-67

26. Tokareva O.S., Pasko O.A., Ushakova N.S., Makartsova E.S., Fedorova L.A. Comprehensive assessment of degradation of snow dump vegetation. Sovremennye Problemy Distantsionnogo Zondirovaniya Zemli iz Kosmosa, 2018, vol. 15, no. 2, pp. 75-83. In Rus.
27. Le Q.B., Nkonya E.M., Mirzabaev A. Biomass productivity-based mapping of global land degradation hotspots. Economics of Land Degradation and Improvement - A Global Assessment for Sustainable Development. Eds. E. Nkonya, A. Mirzabaev, J. von Braun. Cham, Springer, 2015. pp. 55-84.

28. Zhou G., Liu X., Liu M. Assimilating remote sensing phenological information into the WOFOST model for rice growth simulation. Remote Sensing, 2019, vol. 11, no. 3, 268. Available at: https://doi.org/10.3390/rs11030268 (accessed 1 February 2019).

29. Padmanaban R., Bhowmik A.K., Cabral P. Satellite image fusion to detect changing surface permeability and emerging urban heat islands in a fast-growing city. PLOS ONE, 2019, vol. 14, no. 1, e0208949. Available at: https://doi.org/10.1371/journal.pone.0208949 (accessed 1 February 2019).

30. Karta Respubliki Irak [Map of the Republic of Iraq]. Available at: https://www.maps-of-the-world.ru/asia/iraq/large-scale-detailedcountry-profile-map-of-iraq-1994 (accessed 1 February 2019).

31. Nations encyclopedia. Iraq. Available at: https://www. nationsencyclopedia.com/economies/Asia-and-thePacific/Iraq.html (accessed 1 February 2019).

32. Climate change knowledge portal. Average monthly temperature \& rainfall for Iraq from 1901-2015. Available at: http://sdwebx.worldbank.org/climateportal/index.cfm?page=countr y_historical_climate\&ThisCCode=IRQ (accessed 1 February 2019).

33. Reki Iraka [The rivers of Iraq]. Available at: http://www.bestcountry.org/asia/iraq/water_source (accessed 1 February 2019).

34. Arai K., Sakashita M., Shigetomi O., Miura Y. Estimation of protein content in rice crop and nitrogen content in rice leaves through regression analysis with NDVI derived from camera mounted radio-control helicopter. International Journal of Advanced Research in Artificial Intelligence, 2014, vol. 3, no. 3, pp. 12-19.

35. Baghdad Climate \& Temperature. Available at: http://www. baghdad.climatemps.com (accessed 1 February 2019).

36. Pogoda $i$ klimat [Wheather and Climate]. Available at: http://www.pogodaiklimat.ru/weather.php?id=40656\&bday $=15 \& \mathrm{f}$ day $=15 \&$ amonth $=3 \&$ ayear $=20$ (accessed 1 February 2019).

37. Rouse J.W., Haas R.H., Scheel J.A., Deering D.W. Monitoring vegetation systems in the Great Plains with ERTS. $3^{\text {rd }}$ Earth Resource Technology Satellite (ERTS) Symposium. Proc. Conf. USA, Washington, 1973. Vol. 1, pp. 309-317.

38. Tucker C.J., Pinzon J.E., Brown M.E., Slayback D.A., Pak E.W., Mahoney R., Vermote E.V., El Saleous N. An extended AVHRR 8$\mathrm{km}$ NDVI dataset compatible with MODIS and SPOT vegetation NDVI data. International Journal of Remote Sensing, 2005, vol. 26, no. 20, pp. 4485-4498.

39. Brown M.E., Pinzón J.E., Didan K., Morisette J.T., Tucker C.J. Evaluation of the consistency of long-term NDVI time series derived from AVHRR, SPOT-vegetation, SeaWiFS, MODIS, and Landsat ETM+ sensors. IEEE Transactions on Geoscience and Remote Sensing, 2006, vol. 44, no. 7, pp. 1787-1793.

40. Beck H.E., McVicar T.R., van Dijk A.I.J.M., Schellekens J., de Jeu R.A.M., Bruijnzeel L.A. Global evaluation of four AVHRR-NDVI data sets: Intercomparison and assessment against Landsat imagery. Remote Sensing of Environment, 2011, vol. 115, no. 10 , pp. $2547-2563$

41. Ahmad W.A., Ahmed M.A., Al-Sharia G.H. Using Normalized Difference Vegetation Index (NDVI) to Identify Hydrocarbon Seepage in Kifl Oil Field and Adjacent Areas South of Iraq. Journal of Environment and Earth Science, 2017, vol. 7, no. 1, pp. 16-30.

42. Hamel S., Garel M., Festa-Bianchet M., Gaillard J.-M. Spring Normalized Difference Vegetation Index (NDVI) predicts annual variation in timing of peak faecal crude protein in mountain ungulates Steeve. Journal of applied ecology, 2009, vol. 46, no. 3, pp. 582-589.

43. Roy D.P., Kovalskyy V., Zhang H.K., Vermote E.F., Yan L., Kumar S.S., Egorov A. Characterization of Landsat-7 to Landsat-8 reflective wavelength and 2 normalized difference vegetation index continuity. Remote Sensing of Environment, 2016, vol. 185, pp. $57-70$.

44. Zhu Z., Woodcock C.E. Continuous change detection and classification of land cover using all available Landsat data. Remote Sensing of Environment, 2014, vol. 144, pp. 152-171. 
45. Kennedy R.E., Yang Z., Cohen W.B. Detecting trends in forest disturbance and recovery using yearly Landsat time series: 1 . LandTrendr - Temporal segmentation algorithms. Remote Sensing of Environment, 2010, vol. 114, no. 12, pp. 2897-2910.

46. Hansen M.C., Egorov A., Potapov P.V., Stehman S.V., Tyukavina A., Turubanova S.A., Roy D.P., Goetz S.J., Loveland T.R., Ju J., Kommareddy A., Kovalskyy V., Forsyth C., Bents T.. Monitoring conterminous United States (CONUS) land cover change with Web-Enabled Landsat Data (WELD). Remote Sensing of Environment, 2014, vol. 140, pp. 466-484.

47. Anderson L.O. Biome-scale forest properties in Amazonia based on field and satellite observations. Remote Sensing, 2012, vol. 4, no. 5, pp. 1245-1271.

48. Potapov P.V., Turubanova S.A., Hansen M.C., Adusei B., Broich M., Altstatt A., Mane L., Justice C.O. Quantifying forest cover loss in Democratic Republic of the Congo, 2000-2010, with Landsat ETM+data. Remote Sensing of Environment, 2012, vol. 122, pp. 106-116.

49. Mjachina K., Hu Z., Chibilyev A. Detection of damaged areas caused by the oil extraction in a steppe region using winter Landsat imagery. Journal of Applied Remote Sensing. 2018, vol. 12, no. 1 ,
016017. Available at: https://doi.org/10.1117/1.JRS.12.016017 (accessed 1 February 2019).

50. Rufin P., Frantz D., Ernst S., Rabe A., Griffiths P., Özdoğan M., Hostert P. Mapping Cropping Practices on a National Scale Using Intra-Annual Landsat Time Series Binning. Remote Sensing, 2019, vol. 11, no. 3, 232. Available at: https://doi.org/10.3390/rs11030232 (accessed 1 February 2019).

51. Earth Explorer (USGS). Available at: https://earthexplorer.usgs.gov/ (accessed 1 February 2019).

52. Zanter K. LANDSAT \& (L8) Data users handbook. Sioux Falls, South Dakota, EROS, 2016. 98 p.

53. Al-doski J., Mansor S.B., Shafri H.Z.M. Image classification in remote sensing. Journal of Environment and Earth Science, 2013, vol. 3, no. 10, pp. 141-148.

54. QGIS. A free and open source geographic information system. Available at: https://qgis.org/en/site/ (accessed 1 February 2019).

55. ERDAS IMAGINE. Available at: https://www.hexagongeospatial. com/products/power-portfolio/erdas-imagine (accessed 1 February 2019).

Received: 2 December 2019.

\section{Information about the authors}

Olga S. Tokareva, Cand. Sc., associate professor, National Research Tomsk Polytechnic University.

Olga A. Pasko, Dr. Sc., professor, National Research Tomsk Polytechnic University.

Saif M. Majid, student, National Research Tomsk Polytechnic University .

Pedro Cabral, $\mathrm{PhD}$, associate professor, Nova University of Lisbon. 